\title{
Locoregional recurrence of triple-negative breast cancer: effect of type of surgery and adjuvant postoperative radiotherapy
}

This article was published in the following Dove Press journal:

Breast Cancer:Targets and Therapy

10 September 2014

Number of times this article has been viewed

Yasser Bayoumi'

Ayman AbdelSamie ${ }^{2}$

Ahmed Abdelsaid ${ }^{3}$

Aida Radwan ${ }^{4}$

'Radiation Oncology, ${ }^{2}$ Medical Oncology, ${ }^{3}$ Surgical Oncology, ${ }^{4}$ Medical Physics, National Cancer Institute, Cairo University, Cairo, Egypt
Correspondence: Yasser Bayoumi Radiation Oncology Department, National Cancer Institute, Cairo, 5046, Egypt

Tel +20966502785290

Email yasserbayoumi777@yahoo.com
Background/purpose: The aim was to evaluate the prognostic significance of postoperative radiotherapy (PORT) and surgical type on local recurrence-free survival (LRFS) and overall survival (OS) in triple-negative breast cancer (TNBC) in the Egyptian population.

Patients and methods: We evaluated 111 patients with stage I-III TNBC diagnosed at our institute during the period from 2004 to 2009. Patients were stratified according to PORT into two groups: a PORT group and a non-PORT group. The influence of PORT and surgical type on LRFS and OS were evaluated. A cross-matching was done to the non-TNBC group of patients to compare the recurrence and survival rates between them and the studied group of TNBC patients.

Results: The mean age of TNBC patients at diagnosis was $63 \pm 7$ years. The majority of the patients had stage III disease $(68.5 \%)$ and $73 \%$ had clinical or pathological positive lymph nodes. Sixty percent (67/111) of patients had modified radical mastectomy and 44/111 (40\%) patients had breast-conserving treatment. PORT was given for $63 \%$ of patients, while systemic treatment was given in $89 \%$ of patients. At the time of analysis, 13 patients $(11 \%)$ developed local recurrence: five of $70(7 \%)$ in the PORT group and eight of $41(19.5 \%)$ in the non-PORT group. Five-year LRFS for the whole group of patients was $88 \% \pm 6 \%$, which was significantly affected by PORT. The surgical type did not affect local recurrence significantly. Five-year OS for the whole group was $54 \% \pm 8 \%$. PORT and surgical type did not affect OS significantly ( $P$-value 0.09 and 0.11 , respectively). Five-year LRFS was $88 \% \pm 6 \%$ and $90 \% \pm 11 \%$ for TNBC and non-TNBC patients, respectively ( $P$-value 0.8 ); however, OS for TNBC was significantly lower than for non-TNBC ( $P$-value 0.04).

Conclusion: TNBC is an aggressive entity compared with other non-TNBC, and these patients benefit from PORT significantly to decrease the risk of local recurrence in all stages. However, further large, prospective, randomized trials are warranted.

Keywords: triple-negative breast cancer, postoperative radiotherapy, local recurrence-free survival, overall survival

\section{Background}

Triple-negative breast cancer (TNBC) is a biological entity that shows negative estrogen receptors (ERs), progesterone receptors (PRs), and human epidermal growth factor receptor 2.,2 Currently, there are no separate guidelines for local treatment of TNBC. Similar to other breast cancer variants, surgery in the form of breast-conserving treatment (BCT) or modified radical mastectomy (MRM) is the primary treatment. ${ }^{3,4}$ Postoperative radiation therapy (PORT) is indicated for all patients with invasive carcinoma of the breast, as part of BCT. PORT is also indicated after MRM in patients with tumors $>5 \mathrm{~cm}$ with or without positive axillary nodes. Many randomized trials over the last several decades 
have demonstrated that PORT following mastectomy or as part of BCT improves local recurrence-free survival (LRFS) and overall survival (OS). ${ }^{5-13}$ This benefit of PORT for TNBC is theoretically valid; however, it has not been widely studied.

The aim of this study was to evaluate the effect of local treatment (type of surgery and PORT) on LRFS and OS in patients with TNBC.

\section{Patients and methods}

We identified 147 patients with TNBC from the database of the pathology department at our institute during the period from 2004 to 2009. The patients were diagnosed as triple negative based on National Cancer Institute guidelines. Negative ER and PR status was labeled when immunostaining was positive in $<1 \%$ of cells. Fluorescence in situ hybridization was used to confirm HER-2/neu status if immunohistochemistry detected $2+$ staining.

Among 147 TNBC patients, 36 patients with stage IV were excluded because of a different treatment approach to stage IV, making the remaining 111 TNBC eligible for the final analysis. Based on PORT, the patients were stratified into two groups: a PORT group and a non-PORT group. Clinical target volume for PORT was chest wall/breast \pm ipsilateral supraclavicular (SCV) fossae. PORT was given by parallel opposed tangential for chest wall/breast were used along with anteroposterior field $\left(12^{\circ}-15^{\circ}\right)$ for ipsilateral SCV and one occasionally one posteroanterior field for SC to achieve adequate dose distribution. The total radiation dose delivered to the chest wall/breast was 50 Gy in 25 fractions ( 2 Gy/fraction) followed by \pm additional scar boost/tumor bed boost of 10-16 Gy in five to eight fractions using photons or 9-12 MeV electrons. Total prescribed radiation dose to the ipsilateral SCV was kept at 46-50 Gy.

The analyzed covariates included patient and tumor characteristics, age, pathological types, tumor grade, tumor size, lymph node status, stage, surgical treatment, and systemic treatment received. The factors of primary interest were the surgical type and PORT.

Further, 111 cases of non-TNBC were chosen and were matched to 111 TNBC cases according to the surgical type, PORT, and American Joint Committee on Cancer stage, to evaluate the difference between the two groups regarding the major prognostic factors (age, primary tumor and nodal staging, PORT, and systemic treatment).

\section{Statistical analysis}

The primary end points were LRFS and OS. LRFS was defined as time from the date of treatment initiation to the date of local recurrence, and OS was defined as time from the date of treatment initiation to the date of mortality due to any cause. Survivors were censored at the date of last contact. The distributions of clinicopathological characteristics according to PORT and TNBC groups were compared using $\chi^{2}$ or Fisher's exact tests. Survival curves were estimated using the Kaplan-Meier method and compared by the log-rank test, and a $P$-value of $<0.05$ was considered statistically significant. Multivariate analysis was also performed to find various prognostic factors for LRFS and OS in TNBC patients. Statistical Package Software System (SPSS) for Windows was used for evaluation of the data.

\section{Results TNBC patients}

Among 111 TNBC patients, 70 patients received PORT and 41 did not receive PORT. The mean age of patients at diagnosis was $63 \pm 7$ years (range $28-81$ years). The patients presented with $\mathrm{T} 1, \mathrm{~T} 2, \mathrm{~T} 3$, and $\mathrm{T} 4$ were $32,42,24$, and 13 patients, respectively. Thirty patients presented with axillary nodenegative disease, 24 with one to three positive axillary nodes, and 58 with four or more axillary node metastasis. The American Joint Committee on Cancer staging distribution was 18,17 , and 76 patients as stage I, II, and III, respectively. The majority of patients were diagnosed with invasive duct carcinoma (94/111). Forty-three patients had Grade III disease and 68/111 patients had GI or GII disease. Sixty-seven patients had MRM performed and 44/111 had BCT. Fifty-one patients received neoadjuvant chemotherapy, 48 received adjuvant chemotherapy, and 12 patients did not receive any systemic treatment. Common neoadjuvant/adjuvant chemotherapy regimens were docetaxel/doxorubicin/cyclophosphamide and paclitaxel/carboplatin.

Table 1 shows the difference between PORT and nonPORT patients regarding the different prognostic factors studied. There was no significant difference between the two groups regarding different prognostic factors except the group of patients with four or more axillary nodes (75\% of the PORT group vs $32 \%$ of the non-PORT group) and more MRM in the non-PORT group ( $71 \%$ vs $54 \%)$. However, the patients who received PORT had a more advanced stage compared with the non-PORT patients.

\section{PORT effect on local recurrence and survival for TNBC patients}

The median follow-up was 64 months (range 24-93 months). At the time of analysis, 13 patients (11\%) developed local recurrence: five of $70(7 \%)$ in the PORT group and eight of 
Table I Patients' characteristics

\begin{tabular}{|c|c|c|c|c|}
\hline \multirow[t]{2}{*}{ Prognostic factor } & \multicolumn{2}{|c|}{$\begin{array}{l}\text { TNBC patient grouping based } \\
\text { on PORT treatment }\end{array}$} & \multirow[t]{2}{*}{$\begin{array}{l}\text { TNBC patients } \\
n=I \mid I(I 00 \%)\end{array}$} & \multirow{2}{*}{$\begin{array}{l}\text { Non-TNBC patients } \\
\text { cross-matching } \\
(\mathrm{n}=\mathrm{I} I \mathrm{I})^{\mathrm{a}}\end{array}$} \\
\hline & $\begin{array}{l}\text { PORT } \\
n=70(63 \%)\end{array}$ & $\begin{array}{l}\text { Non-PORT } \\
n=4 \mid(37 \%)\end{array}$ & & \\
\hline Age, years & $54 \pm 7$ & $68 \pm 13$ & $63 \pm 7$ (range 28-8I) & $60 \pm 11$ \\
\hline \multicolumn{5}{|l|}{ Pathology type } \\
\hline IDC & $63(90 \%)$ & 31 (76\%) & 94 (85\%) & $80(72 \%)$ \\
\hline ILC & $5(7 \%)$ & $9(22 \%)$ & $14(13 \%)$ & $22(20 \%)$ \\
\hline Others & $2(3 \%)$ & I (2\%) & $3(2 \%)$ & $9(8 \%)$ \\
\hline \multicolumn{5}{|l|}{ T stage } \\
\hline TI & 20 (29\%) & 12 (29\%) & 32 (29\%) & 24 (22\%) \\
\hline $\mathrm{T} 2$ & $24(34 \%)$ & I 8 (44\%) & $42(38 \%)$ & $50(45 \%)$ \\
\hline T3 & 17 (24\%) & $7(17 \%)$ & $24(22 \%)$ & $17(15 \%)$ \\
\hline T4 & $9(13 \%)$ & $4(10 \%)$ & $13(11 \%)$ & $20(18 \%)$ \\
\hline \multicolumn{5}{|l|}{ Lymph node status } \\
\hline No & II (16\%) & 18 (44\%) & $29(26 \%)$ & $28(25 \%)$ \\
\hline $\mathrm{NI}-3$ & $14(20 \%)$ & $10(24 \%)$ & $24(22 \%)$ & $17(15 \%)$ \\
\hline $\mathrm{N} \geq 4$ & 45 (64\%) & 13 (32\%) & 58 (52\%) & $66(60 \%)$ \\
\hline \multicolumn{5}{|l|}{ AJCC stage } \\
\hline I & $8(11 \%)$ & $10(24 \%)$ & $18(16 \%)$ & 14 (I2\%) \\
\hline II & $9(13 \%)$ & $8(20 \%)$ & $17(15 \%)$ & $25(23 \%)$ \\
\hline III & $53(76 \%)$ & $23(56 \%)$ & $76(69 \%)$ & $72(65 \%)$ \\
\hline \multicolumn{5}{|l|}{ Grade } \\
\hline I & $10(14 \%)$ & 14 (34\%) & $24(22 \%)$ & $19(17 \%)$ \\
\hline 2 & $33(47 \%)$ & II (27\%) & $44(40 \%)$ & $35(32 \%)$ \\
\hline 3 & 27 (39\%) & $16(39 \%)$ & $43(38 \%)$ & $57(51 \%)$ \\
\hline \multicolumn{5}{|l|}{ Surgery } \\
\hline MRM & $38(54 \%)$ & 29 (71\%) & $67(60 \%)$ & $67(60 \%)$ \\
\hline BCT & 32 (46\%) & 12 (29\%) & 44 (40\%) & 44 (40\%) \\
\hline \multicolumn{5}{|l|}{ Chemotherapy } \\
\hline Neoadjuvant & 35 (50\%) & $16(39 \%)$ & 51 (46\%) & $33(30 \%)$ \\
\hline Adjuvant & $28(40 \%)$ & $20(49 \%)$ & $48(43 \%)$ & $43(39 \%)$ \\
\hline None & $7(10 \%)$ & $5(12 \%)$ & $12(11 \%)$ & $7(6 \%)$ \\
\hline Hormonal & 0 & 0 & 0 & 87 (78\%) \\
\hline
\end{tabular}

Note: a 83 received radiation and 28 did not receive radiation (matching mainly done based on surgical type and stage).

Abbreviations: AJCC, American Joint Committee on Cancer; BCT, breast-conserving treatment; IDC, invasive duct carcinoma; ILC, invasive lobular carcinoma; MRM, modified radical mastectomy; PORT, postoperative radiotherapy; TNBC, triple-negative breast cancer.

$41(19.5 \%)$ in the non-PORT group. Local recurrence in the PORT group was documented as one patient stage I, one patient stage II, and three patients stage III. On the other hand, local recurrence was documented in three patients stage II and five patients stage III of the non-PORT group. The risk of local recurrence was observed as higher during the first 2 years after primary treatment and then after 5 years. All local failures were seen in the presence of distant metastasis.

Five-year LRFS for the whole group of patients was $88 \% \pm 6 \%$, which was significantly affected by PORT being given (Table 2). Five-year LRFS for the PORT group was $94 \% \pm 4 \%$ compared with $82 \% \pm 7 \%$ for the non-PORT group, with a $P$-value of 0.001 , as shown in Figure 1A. Surgical type did not affect local recurrence significantly. Five-year LRFS was $85 \% \pm 5 \%$ compared with $90 \% \pm 8 \%$ for MRM and BCT patients, respectively, with a $P$-value of 0.2 .
Table 2 Five-year-LRFS and 5-year OS in TNBC

\begin{tabular}{lllll}
\hline Prognostic factor & $\begin{array}{l}\text { 5-year } \\
\text { LRFS (\%) }\end{array}$ & P-value & $\begin{array}{l}\text { 5-year } \\
\text { OS (\%) }\end{array}$ & P-value \\
\hline All patients & & & & \\
TNBC (I I I patients) & $88 \pm 6$ & 0.8 & $54 \pm 8$ & 0.04 \\
$\begin{array}{l}\text { Non-TNBC (III patients) } \\
\text { TNBC patients }\end{array}$ & $90 \pm$ II & & $72 \pm 10$ & \\
Radiation therapy & & & & \\
$\quad$ PORT & $94 \pm 4$ & 0.001 & $65 \pm 13$ & 0.09 \\
$\quad$ Non-PORT & $82 \pm 7$ & & $5 I \pm 6$ & \\
$\begin{array}{l}\text { Surgical treatment } \\
\quad \text { MRM (67 patients) }\end{array}$ & $85 \pm 5$ & 0.2 & $43 \pm 7$ & 0.11 \\
$\quad$ BCT (44 patients) & $90 \pm 8$ & & $57 \pm 10$ & \\
Chemotherapy & & & & \\
$\quad \begin{array}{l}\text { Neoadjuvant } \\
\quad \text { (5I patients) }\end{array}$ & $87 \pm 5$ & 0.4 & $55 \pm 5$ & 0.3 \\
$\quad$ Adjuvant (48 patients) & $86 \pm 6$ & & $58 \pm 4$ & \\
\hline
\end{tabular}

Abbreviations: $B C T$, breast-conserving treatment; LRFS, local recurrencefree survival; MRM, modified radical mastectomy; OS, overall survival; PORT, postoperative radiotherapy; TNBC, triple-negative breast cancer. 
A

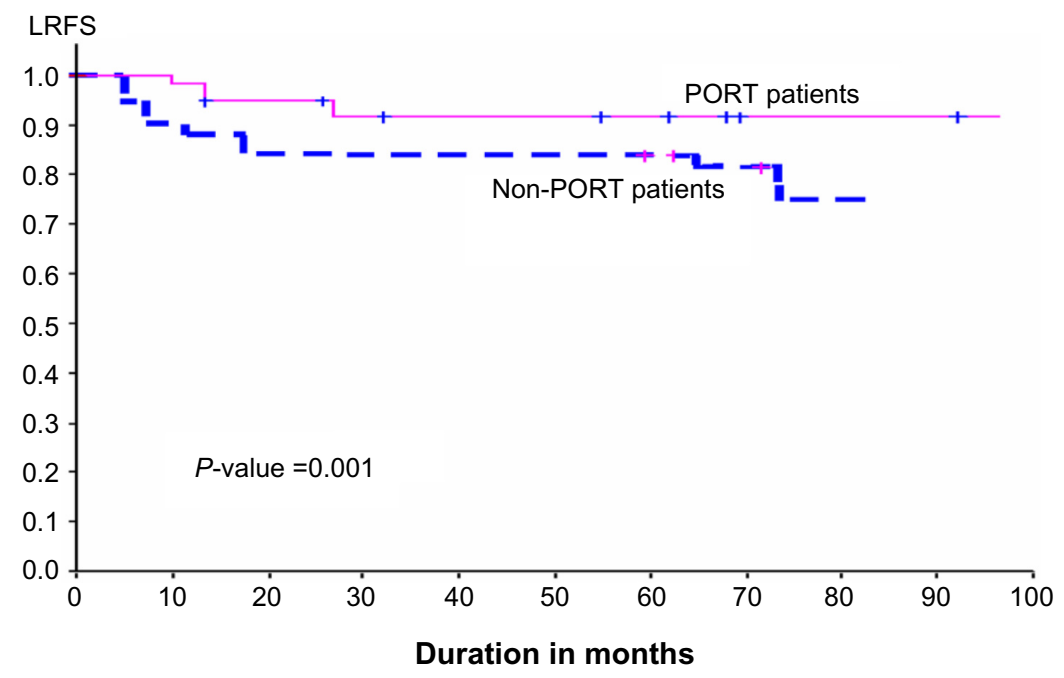

B LRFS

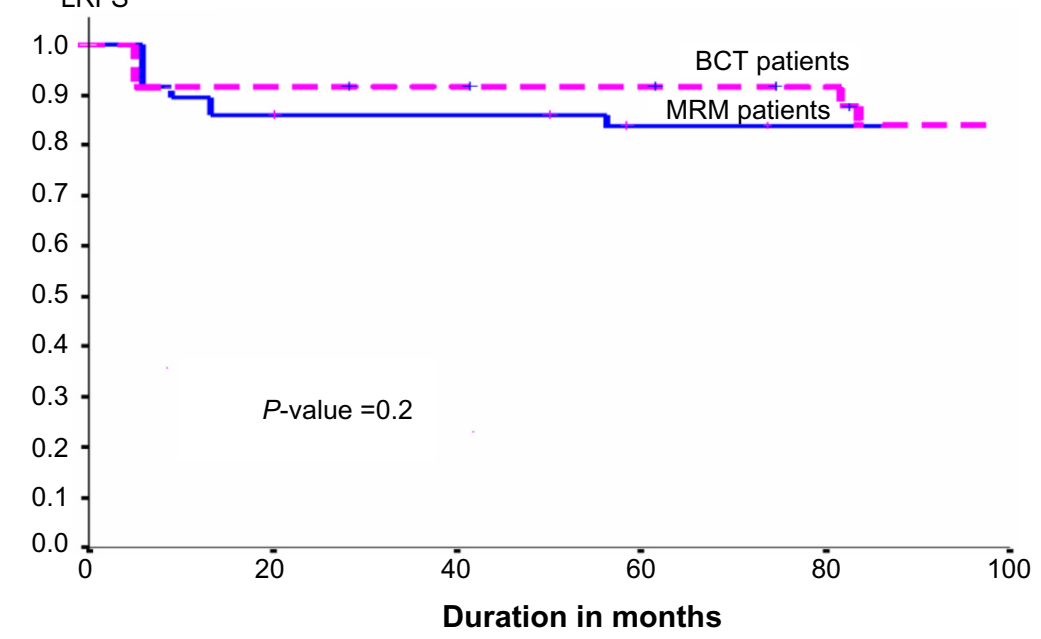

C

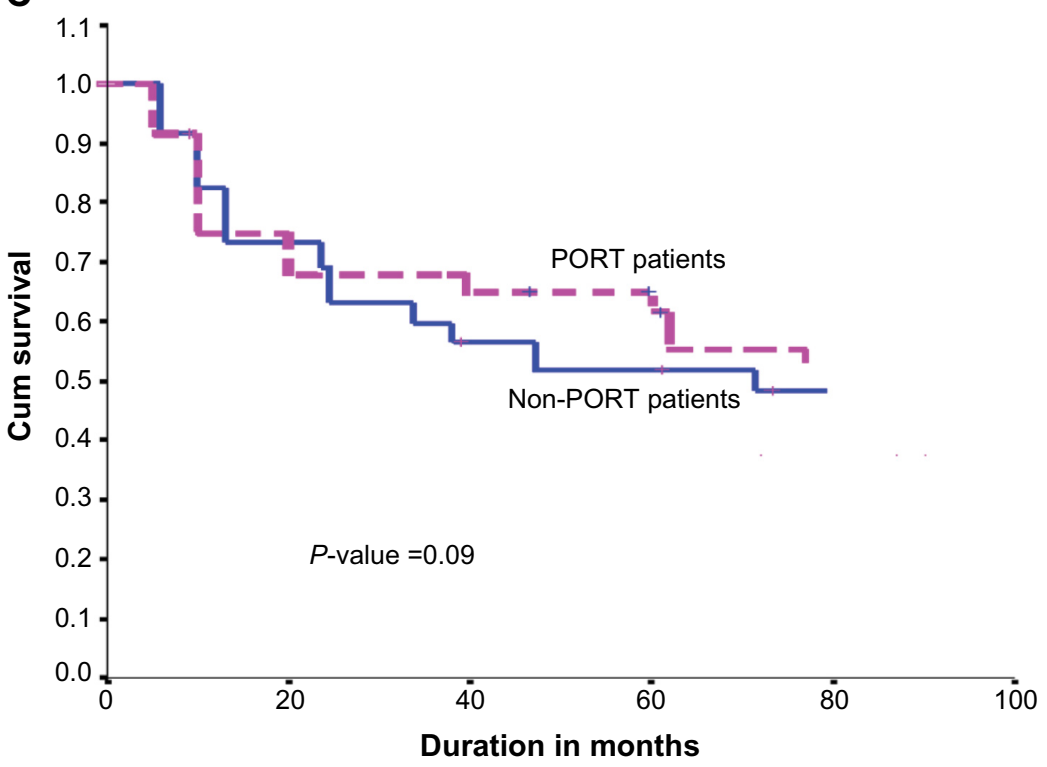

Figure I (Continued) 


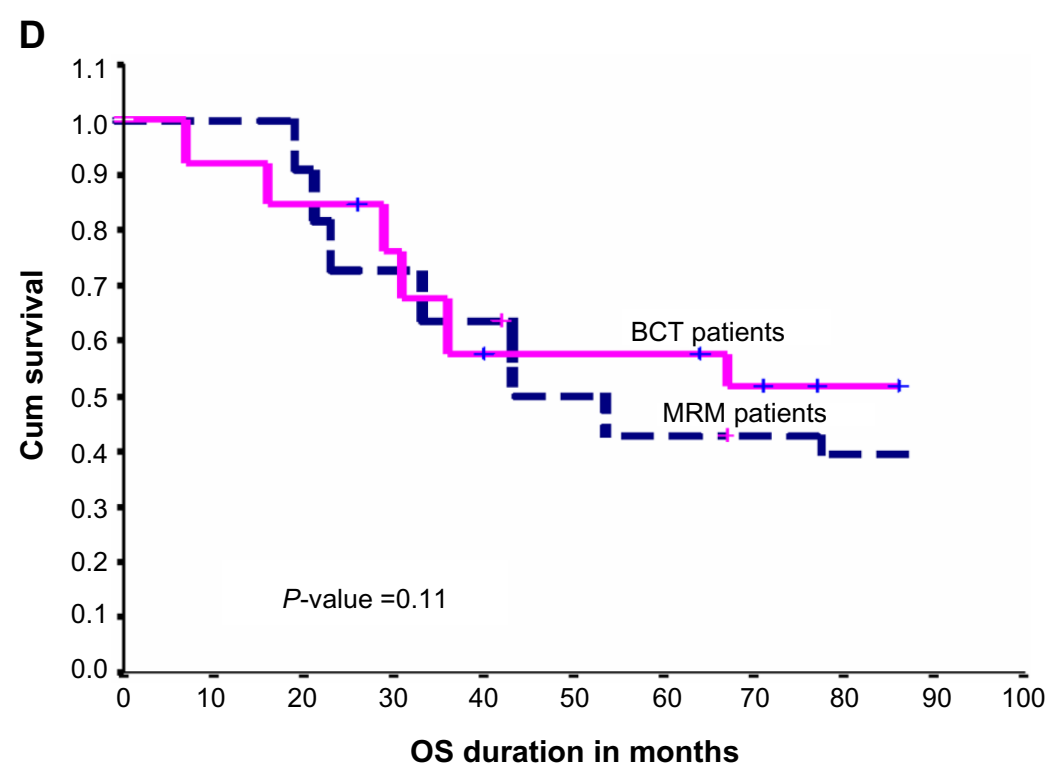

Figure I (A) Effect of PORT on LRFS in TNBC patients. (B) Effect of surgical type on LRFS in TNBC patients. (C) Effect of PORT on OS in TNBC patients. (D) Effect of surgical type on OS in TNBC patients.

Abbreviations: BCT, breast-conserving treatment; LRFS, local recurrence-free survival; MRM, modified radical mastectomy; OS, overall survival; PORT, postoperative radiotherapy; TNBC, triple-negative breast cancer.

Twenty-three patients (56\%) died at the time of analysis, compared with 31 patients (44\%) in the non-PORT group and the PORT group, respectively. Five-year OS for TNBC patients was $54 \% \pm 8 \%$ (Figure 1B). Five-year OS for the PORT group was $65 \% \pm 13 \%$ compared with $51 \% \pm 6 \%$ for the non-PORT group of patients ( $P$-value 0.09 ), as shown in Figure $1 \mathrm{C}$. The type of surgery also did not affect OS significantly ( $P$-value 0.11$)$. Five-year OS for MRM patients was $43 \% \pm 7 \%$ in comparison with BCT patients, which was $57 \% \pm 10 \%$, as shown in Figure 1D.

\section{Comparing TNBC with non-TNBC}

There was no significant difference between the two groups regarding the major prognostic factors: age, $\mathrm{T}$ stage, nodal disease, histopathological type, and systemic treatment (see Table 1). Eighty-three (75\%) patients in the non-TNBC group received PORT, compared with $63 \%$ of the TNBC patients. Five-year LRFS was $88 \% \pm 6 \%$ and $90 \% \pm 11 \%$ for TNBC and non-TNBC patients, respectively ( $P$-value 0.8$)$, as illustrated in Figure $2 \mathrm{~A}$. OS was $72 \% \pm 10 \%$ for nonTNBC patients compared with $54 \% \pm 8 \%$ for TNBC patients ( $P$-value 0.04$)$, as shown in Figure 2B.

\section{Discussion}

Population-based studies have confirmed that patients with TNBC generally experience a more aggressive clinical course, with increased risk of disease progression and poorer OS. ${ }^{1}$
There has been much debate as to whether TNBC could benefit from radiation therapy regardless of surgical intervention. Therefore, several retrospective studies have analyzed the role of radiation therapy in TNBC, but their findings are conflicting. ${ }^{14-19}$ The aim of our study was to evaluate PORT and surgical type as prognostic factors for locoregional recurrence in TNBC patients.

In our study, we could identify that the PORT group had worse prognostic factors, and this was the main reason for the primary physician referral to the radiotherapy department, as $75 \%$ of PORT patients had stage III, compared with non-PORT patients (56\%). Despite this, the patients in the non-PORT group experienced more local recurrences (19.5\%) compared with the PORT group (7\%).

Our data are comparable with data from Dragun et al, ${ }^{16}$ who investigated the influence of PORT in TNBC patients after BCS. In this study, 53 patients (69\%) received PORT. Three-year LRFS for PORT patients was higher than for non-PORT patients ( $80 \%$ vs 58\%, respectively, $P=0.049$ ). However, these results are much inferior compared with other similar TNBC data, including our study. ${ }^{17,18}$ PORT after MRM in T1-2N0 is not usually recommended; however, Abdulkarim et $\mathrm{al}^{19}$ reported that post-MRM T1-T2N0 TNBC patients without PORT are at higher risk of local recurrence compared with lumpectomy and PORT $(P=0.026)$. Jagsi et $\mathrm{al}^{21}$ and Truong et $\mathrm{al}^{22}$ also concluded that PORT is needed after MRM, even in T1-2N0 TNBC patients. 


\section{A}
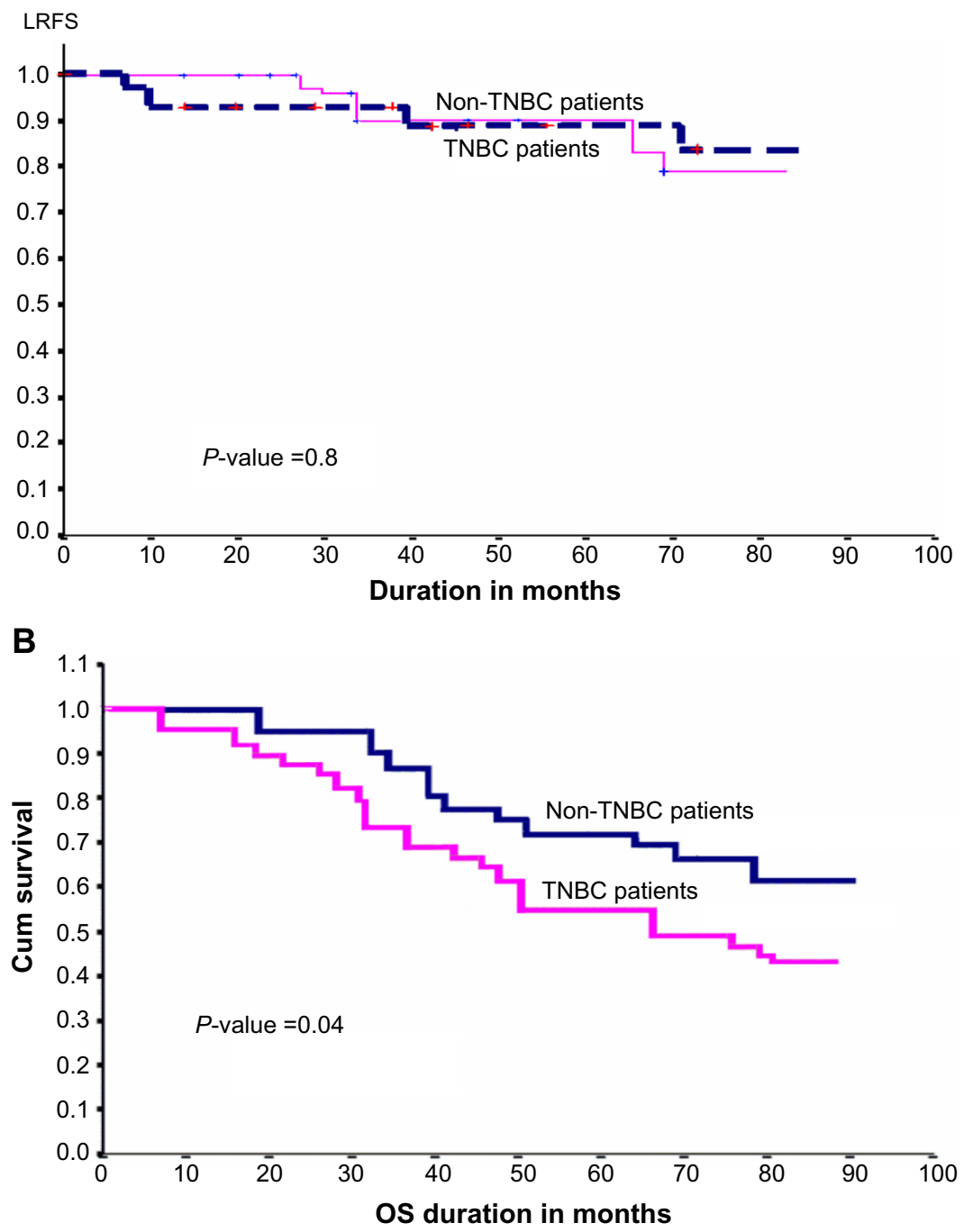

Figure 2 (A) Cross-matching between TNBC patients and non-TNBC patients: LRFS difference. (B) OS difference between TNBC patients and non-TNBC patients. Abbreviations: LRFS, local recurrence-free survival; OS, overall survival; PORT, postoperative radiotherapy; TNBC, triple-negative breast cancer.

Our results are also better than data from Kyndi et al, ${ }^{17}$ who showed $15 \%$ locoregional recurrences in PORT compared with $32 \%$ in non-PORT $(P<0.001)$. The possible reason could be that in the Kyndi et al data more advanced-stage TNBC patients were included. As reported in our study, Dent et al $^{1}$ also reported that the majority of recurrences in TNBC patients occurred at the first 3 years of follow-up.

In our study, there was no significant difference in OS between PORT and non-PORT groups, which is consistent with results of Kyndi et al ${ }^{17}$ data (39\% in PORT and 32\% in non-PORT; $P=0.4$ ).

The aggressive nature of TNBC leads to the logical assumption of superiority of MRM over BCT among a wide sector of oncologists. However, in our study, the surgical type did not affect the local recurrence or OS significantly, which is similar to findings of the Parker et $\mathrm{a}^{23}$ study based on a retrospective analysis of 202 patients with TNBC. In this study, $30 \%$ of the patients underwent $\mathrm{BCT}$ and $70 \%$ patients underwent MRM. Five-year disease free survival rates for the BCT and mastectomy groups were $68 \%$ and $57 \%$, respectively $(P=0.14)$, and 5 -year OS was better for the BCT group compared with the MRM group ( $89 \%$ vs $69 \% ; P=0.01$ ). They concluded that BCT is not contraindicated in TNBC.

Recent advances have changed the treatment strategy for breast cancer. Biological behavior of breast cancer has been investigated by molecular profiling with the use of array technology. It was tempting, therefore, to collect the survival data of 111 matched cases of breast cancer patients known to be non-TNBC and to compare them with TNBC in our study. Despite matching in the major prognostic variable, there is a potential statistical bias, which was a limitation of our study. It is interesting that our data are in agreement 
with those of Millar et al, ${ }^{24}$ who retrospectively reviewed 753 breast cancer patients ( 98 with TNBC) and showed that 5 -year local recurrence rates were $2.3 \%, 4.6 \%$, and $3.2 \%$ for luminal A/B, HER2 overexpression, and TNBC, respectively, without any statistical significance.

In contrast to that, Solin et $\mathrm{a}^{25}$ compared 519 patients who underwent $\mathrm{BCT}$ according to TNBC group (90 patients) with a non-TNBC group. The 8 -year local recurrence rate was $8 \%$ for TNBC versus $4 \%$ for non-TNBC $(P=0.041)$. However, this difference was lost following multivariate analysis.

It is interesting to mention that in our study OS differed significantly between TNBC $(54 \% \pm 8 \%)$ and non-TNBC $(72 \% \pm 10 \%)$. These results are comparable with those of Liedtke et $\mathrm{al}^{26}$ (1,118 breast cancer patients), who reported lower 3-year survival rates in TNBC (74\%) compared with non-TNBC $(89 \%)(P<0.0001)$.

A population-based study of medical records from a midwestern community oncology practice analyzed 151 TNBC patients out of 1,134 stage I-III patients. They reported poorer OS for TNBC, with a mortality hazard ratio of 1.75 (95\% confidence interval 1.01-3.03). ${ }^{27}$ These results are also in agreement with our results.

Apart from the aforementioned strengths, the major limitations of our study were that 1) it was a retrospective analysis, 2) there was potential selection/information and confounding bias, and 3) pathological complete response or pathological no residual (ypT0) after neoadjuvant chemotherapy and effect of PORT on ypT0N0 in TNBC patients were not studied.

\section{Conclusion}

In conclusion, the results described here demonstrate that TNBCs are associated with poor LRFS and OS and high mortality rates compared with other breast cancer types. LRFS can be enhanced in TNBC patients by adding PORT, without any need for aggressive surgery. However, further large randomized trials are warranted.

\section{Disclosure}

The authors have no potential conflicts of interest in this work. No grants or funds have been received for this study.

\section{References}

1. Dent R, Trudeau M, Pritchard KI, et al. Triple negative breast cancer: clinical features and patterns of recurrence. Clin Cancer Res. 2007;13: 4429-4434.

2. Bauer KR, Brown M, Cress RD, Parise CA, Caggiano V. Descriptive analysis of estrogen receptor (ER)-negative, progesterone receptor (PR)-negative, and HER2-negative invasive breast cancer, the so-called triple-negative phenotype: a population-based study from the California Cancer Registry. Cancer. 2007;109:1721-1728.
3. Fisher B, Anderson S, Bryant J, et al. Twenty-year follow-up of a randomized trial comparing total mastectomy, lumpectomy, and lumpectomy plus irradiation for the treatment of invasive breast cancer. $N E n g l$ J Med. 2002;347(16):1233-1241.

4. Blichert-Toft M, Rose C, Andersen JA, et al. Danish randomized trial comparing breast conservation therapy with mastectomy: six years of life-table analysis. Danish Breast Cancer Cooperative Group. J Natl Cancer Inst Monogr. 1992;11:19-25.

5. Overgaard M, Hansen PS, Overgaard J, et al. Postoperative radiotherapy in high-risk premenopausal women with breast cancer who receive adjuvant chemotherapy. Danish Breast Cancer Cooperative Group 82b Trial. N Engl J Med. 1997;337(14):949-955.

6. Ragaz J, Jackson SM, Le N, et al. Adjuvant radiotherapy and chemotherapy in node-positive premenopausal women with breast cancer. N Engl J Med. 1997;337(14):956-962.

7. Ragaz J, Olivotto IA, Spinelli JJ, et al. Locoregional radiation therapy in patients with high-risk breast cancer receiving adjuvant chemotherapy: 20 -year results of the British Columbia randomized trial. J Natl Cancer Inst. 2005;97(2):116-126.

8. Overgaard M, Jensen MB, Overgaard J, et al. Postoperative radiotherapy in high-risk postmenopausal breast cancer patients given adjuvant tamoxifen: Danish Breast Cancer Cooperative Group DBCG 82c randomized trial. Lancet. 1999;353(9165):1641-1648.

9. Nielsen HM, Overgaard M, Grau C, Jensen AR, Overgaard J. Study of failure pattern among high-risk breast cancer patients with or without postmastectomy radiotherapy in addition to adjuvant systemic therapy: long-term results from the Danish Breast Cancer Cooperative Group DBCG 82 b and c randomized studies. $J$ Clin Oncol. 2006;24(15): 2268-2275.

10. Blichert-Toft M, Rose C, Andersen JA, et al. Danish randomized trial comparing breast conservation therapy with mastectomy: six years of life-table analysis. Danish Breast Cancer Cooperative Group. J Natl Cancer Inst Monogr. 1992;11:19-25.

11. van Dongen JA, Bartelink H, Fentiman IS, et al. Randomized clinical trial to assess the value of breast-conserving therapy in stage I and II breast cancer, EORTC 10801 trial. J Natl Cancer Inst Monogr. 1992;11: $15-18$.

12. Veronesi U, Cascinelli N, Mariani L, et al. Twenty-year follow-up of a randomized study comparing breast-conserving surgery with radical mastectomy for early breast cancer. $N$ Engl J Med. 2002;347(16): $1227-1232$.

13. van Dongen JA, Voogd AC, Fentiman IS, et al. Long-term results of a randomized trial comparing breast-conserving therapy with mastectomy: European Organization for Research and Treatment of Cancer 10801 trial. J Natl Cancer Inst. 2000;92(14):1143-1150.

14. Haffty BG, Yang Q, Reiss M, et al. Locoregional relapse and distant metastasis in conservatively managed triple negative early-stage breast cancer. J Clin Oncol. 2006;24:5652-5657.

15. Panoff JE, Hurley J, Takita C, et al. Risk of locoregional recurrence by receptor status in breast cancer patients receiving modern systemic therapy and post-mastectomy radiation. Breast Cancer Res Treat. 2011;128:899-906.

16. Dragun AE, Pan J, Rai SN, Kruse B, Jain DL. Locoregional recurrence in patients with triple-negative breast cancer: preliminary results of a single institution study. Am J Clin Oncol. 2011;34:231-237.

17. Kyndi M, Sorensen FB, Knudsen H, et al. Estrogen receptor, progesterone receptor, HER-2, and response to postmastectomy radiotherapy in highrisk breast cancer: the Danish Breast Cancer Cooperative Group. J Clin Oncol. 2008;26:1419-1426.

18. Freedman GM, Anderson PR, Li T, et al. Locoregional recurrence of triple-negative breast cancer after breast-conserving surgery and radiation. Cancer. 2009;115(5):946-951.

19. Abdulkarim B, Cuartero J, Hanson J, et al. Increased risk of locoregional recurrence for women with T1-2N0 triple-negative breast cancer treated with modified radical mastectomy without adjuvant radiation therapy compared with breast-conserving therapy. J Clin Oncol. 2011;29: $2852-2858$. 
20. Wang J, Shi M, Ling R, et al. Adjuvant chemotherapy and radiotherapy in triple-negative breast carcinoma: a prospective randomized controlled multi-center trial. Radiother Oncol. 2011;100:200-204.

21. Jagsi R, Raad RA, Goldberg S, et al. Locoregional recurrence rates and prognostic factors for failure in node-negative patients treated with mastectomy: implications for postmastectomy radiation. Int J Radiat Oncol Biol Phys. 2005;34:1035-1039.

22. Truong PT, Lesperance M, Culhaci A, et al. Patient subsets with T1-T2, node negative breast cancer at high locoregional recurrence risk after mastectomy. Int J Radiat Oncol Biol Phys. 2005;62: 175-182.

23. Parker CC, Ampil F, Burton G, et al. Is breast conservation therapy a viable option for patients with triple-receptor negative breast cancer? Surgery. 2010;148:386-391.
24. Millar EK, Graham PH, O'Toole SA, et al. Prediction of local recurrence, distant metastases, and death after breast-conserving therapy in early-stage invasive breast cancer using a five-biomarker panel. $J$ Clin Oncol. 2009;27:4701-4708.

25. Solin LJ, Hwang WT, Vapiwala N. Outcome after breast conservation treatment with radiation for women with triple-negative early-stage invasive breast carcinoma. Clin Breast Cancer. 2009;9:96-100.

26. Liedtke C, Mazouni C, Hess KR, et al. Response to neoadjuvant therapy and long-term survival in patients with triple-negative breast cancer. J Clin Oncol. 2008;26(8):1275-1281.

27. Onitilo AA, Engel JM, Greenlee RT, Mukesh BN. Breast cancer subtypes based on ER/PR and HER2 expression: comparison of clinicopathologic features and survival. Clin Med Res. 2009;7:4-13.

\section{Publish your work in this journal}

Breast Cancer: Targets and Therapy is an international, peerreviewed open access journal focusing on breast cancer research, identification of therapeutic targets and the optimal use of preventative and integrated treatment interventions to achieve improved outcomes, enhanced survival and quality of life for the cancer patient.
View the full aims and scopes of this journal here. The manuscript management system is completely online and includes a very quick and fair peer-review system, which is all easy to use. Visit http:// www.dovepress.com/testimonials.php to read real quotes from published authors.

Submit your manuscript here: http://www.dovepress.com/breast-cancer---targets-and-therapy-journal 